\title{
ОРГАНИЗАЦИОННО-ЭКОНОМИЧЕСКОЕ СТИМУЛИРОВАНИЕ УСТОЙЧИВОГО ТЕХНОЛОГИЧЕСКОГО РАЗВИТИЯ РОССИЙСКИХ НЕФТЕГАЗОВЫХ КОМПАНИЙ
}

\author{
(c) 2020 Кузнецова Дарья Сергеевна \\ аспирант кафедры экономической теории \\ Московский государственный институт международных отношений (университет), Россия, Москва \\ E-mail: dashaku@list.ru
}

\begin{abstract}
Нефтегазовая отрасль страны остро нуждается в применении новейших технологий в связи с падением цен на нефть, истощением традиционных запасов, повышенным уровнем износа инфраструктуры, сохранением бюрократических барьеров и санкционными ограничениями, которые ощутимо сказались на деятельности ведущих российских компаний. В основном внимание государства направлено на поддержку инновационной активности и развитие отечественных технологий в среде крупного и среднего бизнеса с достижением уровня зарубежных конкурентов. В работе проведен анализ современных возможностей стимулирования устойчивого технологического развития нефтегазовых компаний России и сформулированы практические рекомендации и лучшие практики.
\end{abstract}

Ключевые слова: инновации, технологии, устойчивость, нефтегазовая отрасль, топливноэнергетический комплекс.

В современных экономических реалиях успешная деятельность компаний возможна лишь при условии целенаправленного новаторства и внедрения прорывных технологий, реализация которых создаст перспективу для повышения эффективности бизнеса и роста его конкурентоспособности на рынке. Так, сложившиеся обстоятельства актуализируют необходимость инновационного развития, в том числе совершенствования и реорганизации деятельности, дополнения имеющихся технологий новыми, обновления производства и замены одних структурных элементов другими [21].

Нефтегазовую отрасль зачастую незаслуженно воспринимают как консервативную, при том что добывающие компании идут в ногу со временем. К примеру, одним из стимулов развития отраслевых технологий в мире стало ухудшение сырьевой базы с 1990-х гг. из-за истощения части крупнейших месторождений [23] (рис. 1).

Цифровизация и прочие инновационные решения - следствие новой технологической революции, Индустрии 4.0, предполагающей развитие и внедрение в отрасли решений по следующим ключевым технологическим направлениям (рис. 2): большие данные (Big Data и искусственный интеллект), промышленный интернет вещей (IоT), роботы и дроны, цифровые двойники, умные материалы, 3D-печать, рас- пределенный реестр (блокчейн).

Инновации комбинируются, в результате чего получается «интеллектуальное» месторождение, позволяющее повысить коэффициент извлечения на 5-10\%, существенно снизить затраты (рис. 3) и увеличить операционную выгоду, по оценкам ВР, на 2-4\% [11].

Большое значение приобретают технологические партнерства и отраслевые консорциумы (международный инвестиционный фонд нефтяных компаний для внедрения технологий улавливания, использования и хранения углерода, а также сокращения выбросов метана и повышения энергоэффективности в области транспорта и промышленности [25], блокчейн-платформа Vakt $[14,22]$ и др.).

В России вклад фактора производительности, или инноваций, оказывает существенное влияние на рост экономики: так, в 2010-14 гг. он обеспечивал $1,1 \%$ ежегодного прироста ВВП. Для реализации масштабной цели по увеличению ВВП на душу населения в 1,5 раза к 2025 г. фактор инноваций должен приносить более $4 \%$ ежегодного прироста ВВП, или порядка 3-6 трлн. руб. $[9,16]$ Между тем, статистические данные свидетельствуют о недостаточных объемах вложения средств в R\&D (рис. 4) и отставании от технологических лидеров (рис. 5).

Более того, успешный рост российской эко- 


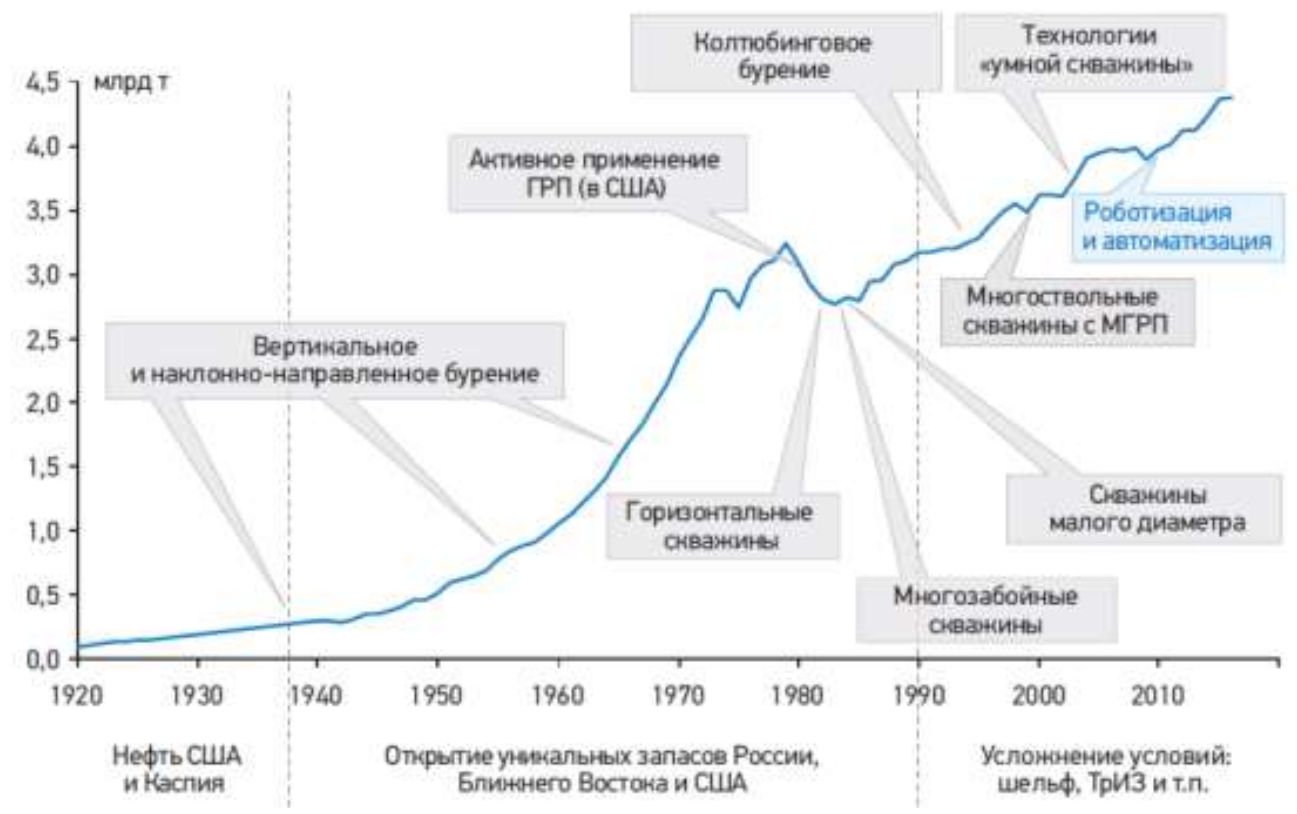

Рисунок 1. Эволюционное развитие технологий бурения скважин Источник: [23]

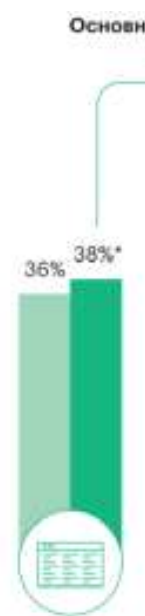

Eonbuine данthe
๓ 6пикайแนи 3-5 пет

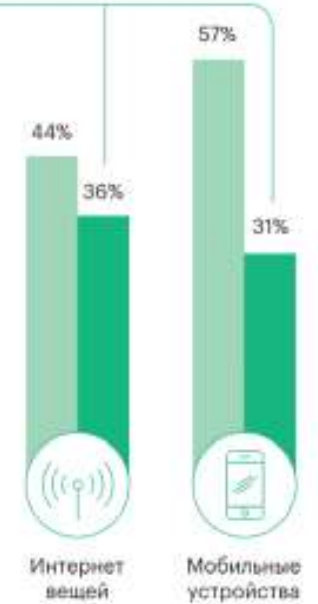

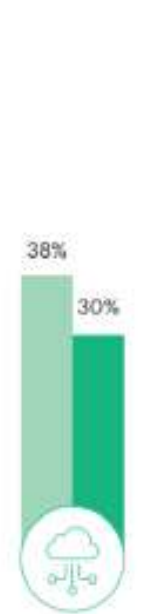

о6naчнte технолотия
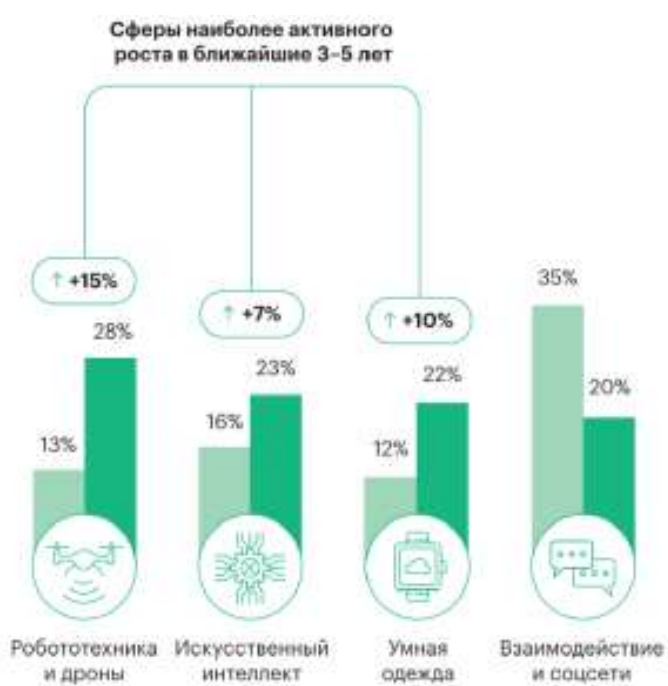

Рисунок 2. Технологические инвестиции нефтяных компаний Источник: [8] 


\begin{tabular}{|c|c|c|c|}
\hline Разработчин & Tеxнопогия & $\begin{array}{l}\text { Впияние на запасы / } \\
\text { добычу }\end{array}$ & $\begin{array}{l}\text { Влиянние } \\
\text { на зиономину }\end{array}$ \\
\hline Shell & Smart Field & $\begin{array}{l}\text { КИН до }+10 \% \\
\text { КИГ до }+5 \%\end{array}$ & $\begin{array}{l}\text { Простои до -10\% } \\
\text { Затраты до -20\% }\end{array}$ \\
\hline Chevron & i-field & $\begin{array}{c}\text { Кин }+6 \% \\
\text { Добына +8\% }\end{array}$ & - \\
\hline BP & Field of the future & Добына +1-2\% & - \\
\hline Petoro & Smart Operations & - & Capex-50\% \\
\hline Statoil & Integrated Operations & Добыча $+20 \%$ & - \\
\hline Halliburton & Real Time Operations & - & Capex-20\% \\
\hline
\end{tabular}

Рисунок 3. Экономический эффект интеллектуального месторождения Источник: [23]

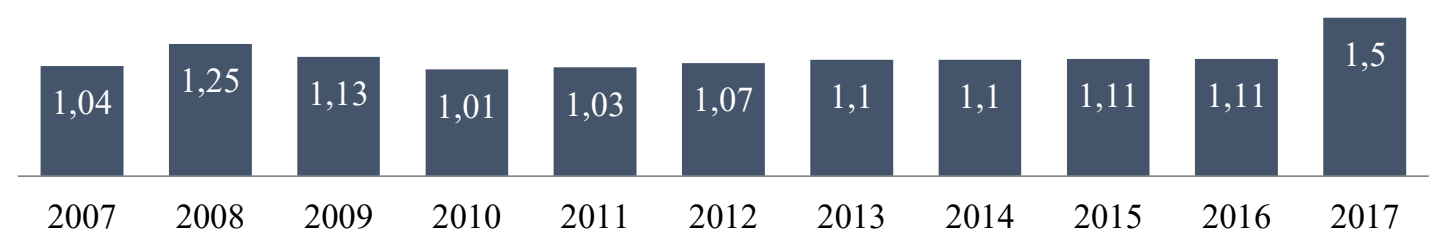

Рисунок 4. Удельный вес внутренних затрат R\&D в объеме ВBП России,\% Источник: составлено автором

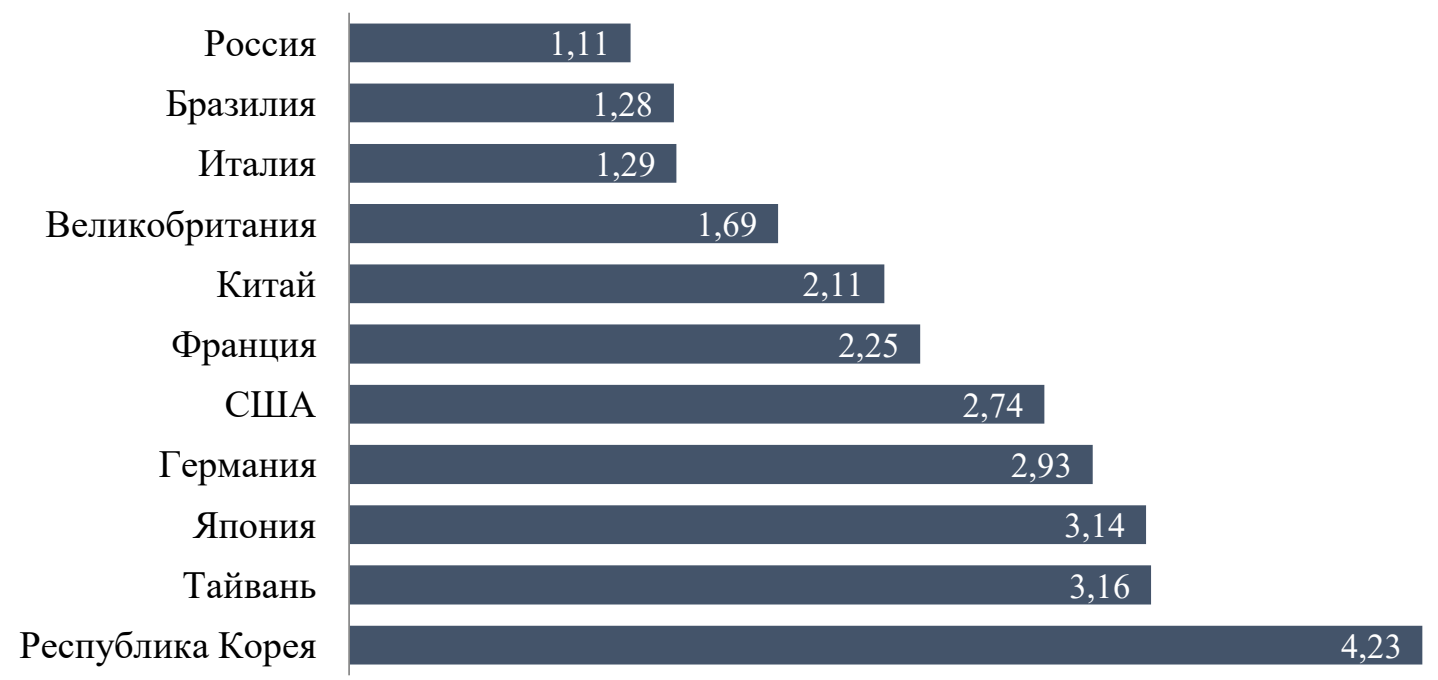

Рисунок 5. Внутренние затраты на R\&D.,\% к BBП страны Источник: составлено автором 
номики предполагает как минимум поддержание текущих объемов добычи, однако традиционные месторождения составляют лишь малое количество запасов нефти и газа в России $(6,5 \%$ и 5,5\% соответственно).

Курс на импортозамещение дополнительно подогревает интерес к отечественным разработкам, но наиболее остро вопрос встает перед компаниями, оказавшимися под санкциями. Существует понимание, что склонность корпораций к ведению собственных разработок, а не к партнерству в сфере или покупке решений у сторонних компаний существенно замедляет их инновационное развитие. В связи с этим на базе Российского энергетического агентства ведётся работа по созданию Центра компетенций импортозамещения и Аналитического центра развития инновационных и импортозамещающих технологий в топливно-энергетическом комплексе. В рамках структур основной задачей Минэнерго будет аккумулирование отраслевого заказа, систематизирование и определение приоритетных направлений разработок и технических заданий; Минпромторг мобилизует потенциал промышленности, обеспечит государственную поддержку проектам и проконтролирует исполнение заказа. Таким образом, определяющим фактором для выбора проекта станет его востребованность на рынке. Центр будет также обеспечивать мониторинг научных изысканий, производства, испытания и применения новейших разработок [13].

Стоит отметить, что многие отечественные инновации представляют собой достойные аналоги зарубежных прорывных технологий. Например, основной спрос на российское программное обеспечение предъявляется в Китае, США, Канаде и странах Юго-Восточной Азии, где находится большое количество старых скважин с падающим объемом добычи [1].

Кроме того, назрела необходимость создания экономических стимулов развития нефтедобывающей отрасли и активной инновационной деятельности [12]. Минэнерго были предложены следующие меры (рис. 6). Так, в 2018 г. принято решение об апробации принципиально нового для российской нефтедобывающей отрасли налога на дополнительный доход от добычи углеводородного сырья (НДД) на некоторых месторождениях - «пилотный периметр НДД» [20].

Компании надеются на полноценное принятие системы НДД в качестве универсального ме- ханизма для всей отрасли взамен действующих сегодня различных адресных льгот, ссылаясь на опыт Канады [2], где в рамках новой фискальной системы учитывается сложность бурения, или Саудовской Аравии [3, 4, 6], снизившей ставку налога на прибыль для Saudi Aramco с 85\% до 50\%. По оценкам, без дополнительных стимулов в ближайшие шесть лет выпадающие доходы бюджета от снижения добычи на месторождениях Западной Сибири могут составить 1,5 трлн. руб. [17]

Государство также играет существенную роль в формировании системы финансирования инноваций, в том числе рынка венчурного, или рискового, капитала. В 2019 г. «Газпром нефть», Газпромбанк, Российская венчурная компания и «ВЭБ Инновации» создали венчурный фонд «Новая индустрия» [7] для инвестиций в технологические компании, специализирующиеся на разработке новых материалов, технологий, продуктов и сервисов для нефтегазовой отрасли, нефтегазохимии и энергетики, в том числе альтернативной. Начальный целевой объем фонда составил 4 млрд. руб.

Тем не менее, инвестиции в России по-прежнему не носят массового характера: нет работающих механизмов, позволявших бы доводить новинки от идеи до реального воплощения. Российские компании привыкли работать в институтской модели инновационной деятельности, когда работы ведутся в соответствии со строгим техническим заданием в рамках выделенного финансирования, а заказчиком выступает государство или компания с государственным участием.

Однако сегодня компании стали все чаще выводить проверку бизнес-гипотез на аутсорсинг своим дочерним фирмам либо научноисследовательским институтам и высшим профильным учебным заведениям, что позволяет быстро тестировать идеи без вложений в обучение персонала и наращивать лабораторную базу. В нефтегазовой отрасли распространена усредненная модель: на начальных стадиях разработки широко вовлекаются сторонние научные организации, а финальные стадии выполняются внутри компании [24].

Государство как основной инвестор, наравне с игроками отрасли, привыкло работать в предсказуемой институтской модели исследований и разработок в рамках научного процесса либо освоения гранта и теперь должно быть готово 
1) Применение повышенного коэффициента амортизации для инвестиций в месторождения Западной Сибири позволит увеличить свободный денежный поток нефтяных компаний в расчете на баррель с \$3,1 до \$6,2, добыча дополнительно вырастет на 460 млн т в 2020-35 гг. , уплаченные налоги - на 5,3 трлн руб., а инвестиции нефтяных компаний - на 1,85 трлн руб.

2) Принятие дополнительных стимулов для геологоразведки

3) Ускоренный переход на налог на добавленный доход (НДД), который может быть применен для всех месторождений Западной Сибири

4) Законодательное изменение критериев и предоставление льгот с момента достижения степени выработанности недр на участке уровня $1 \%$ вместо фиксации конкретных дат начала и окончания действия льгот по налогу на добычу полезных ископаемых (НДПИ). Ожидаемый результат до 2021 г. - около 25 млн т дополнительной добычи нефти и порядка 265 млрд руб. поступлений в бюджет

5) Стимулирование третичных методов нефтеотдачи, использование которых экономически невыгодно, с применением понижающего коэффициента НДПИ для дополнительных объемов добычи

6) Стимулирование нефтяных оторочек - частей нефтегазовой либо нефтегазоконденсатной залежи, где газ занимает существенно больший объем, чем нефть, разработка которых на сегодняшний момент невыгодна

Рисунок 6. Меры по развитию нефтедобывающей отрасли в России

Источник: составлено автором

к условиям рисковой модели, когда открытия совершаются ради коммерческого результата и преимущества на рынке. Первостепенными задачами в рамках инвестиционной политики в целом являются улучшение соотношения между инвестициями в ресурсодобывающие, перерабатывающие и потребляющие отрасли, перераспределение инвестиций в пользу отраслей, обеспечивающих ускорение научно-технического прогресса, и увеличение вложений в человеческий капитал [18].

Наконец, интерес представляет модель «тройной спирали» (triple helix model) профессоров Генри Ицковица (Стэнфордский университет) и Лойета Лейдесдорфа (Амстердамский университет), основанная на идеях об эффективном сотрудничестве государства, бизнеса и университетов для ускорения инновационного развития. Государство предоставляет венчурный капитал стартапам, формируя бизнес-функции; компании создают корпоративные университе- ты, занимаются профессиональным обучением и проводят исследования собственными силами или в партнерстве с вузами; университеты помимо научно-образовательной деятельности способствуют появлению в инкубаторах новых фирм и трансферу технологий внутри кампуса $[5,15]$.

В России модель реализуется посредством открытия базовых кафедр высокотехнологичных компаний в ведущих университетах страны, а также в формате сотрудничества с научноисследовательскими центрами [10].

$* * *$

С учётом возможностей научно-технологического развития российской нефтегазовой отрасли и перспектив организационно-экономического стимулирования инновационной деятельности компаний, можно выделить следующие основные направления $R \& D$ :

1) создание в краткосрочной перспективе 
критически важных инноваций для устойчивого функционирования топливно-энергетического комплекса в условиях политики импортозамещения;

2) разработка и промышленное освоение отечественных технологий, а также трансфер и обеспечение высокой степени локализации прорывных зарубежных решений в целях технического перевооружения и модернизации предприятий отрасли;

3) в долгосрочной перспективе интерес представляют фундаментальные исследования и развитие научно-технологического потенциала страны для перехода к энергетике будущего;

4) особая роль отводится внедрению энер- гоэффективной составляющей для достижения полного соответствия научно-технологического прогресса в российской энергетике принципам устойчивого развития [19].

Нефтегазовые компании, вне зависимости от того, являются ли они государственными или частными, постоянно находятся в поиске лучших технологических решений для реализации своих проектов. Вопросы повышения эффективности и оптимизации издержек - это постоянная работа, поскольку только те игроки, которые готовы наращивать компетенции под тренды времени и требования инновационного развития, смогут сохранить лидерство в конкурентной борьбе.

\section{Библиографический список}

1. Big Data подкачают [Электронный ресурс] // Российская Газета [Офиц. сайт].- Режим доступа: https:// rg.ru/2019/04/16/iskusstvennyj-intellekt-pomozhet-uvelichit-dobychu-nefti.html

2. ЕY: Канада: пересмотр системы роялти в провинции Альберта [Электронный ресурс] // Аналитический центр при Правительстве Российской Федерации [Офиц. сайт].- Изменения и тенденции в регулировании ТЭК России и мира: в фокусе III квартал 2016.- Октябрь 2016.- Режим доступа: http://ac.gov.ru/files/ publication/a/10552.pdf

3. Saudi Aramco была самой прибыльной компанией в мире в 2018 году [Электронный ресурс] // Вести Экономика [Офиц. сайт]. - Режим доступа: https://www.vestifinance.ru/articles/117117

4. Saudi Aramco оставила Apple далеко позади [Электронный ресурс] // Ведомости [Офиц. сайт].- Режим доступа: https://www.vedomosti.ru/business/articles/2019/04/01/797982-aramco-apple

5. Вихри «Тройной спирали» [Электронный ресурс] // Эксперт Онлайн [Офиц. сайт].- Режим доступа: https:// expert.ru/siberia/2014/42/vihri-trojnoj-spirali/

6. Государственные стимулы: за счет чего развивается Saudi Aramco [Электронный ресурс] // Газета.Ru [Oфиц. сайт].- Режим доступа: https://www.gazeta.ru/business/2019/04/10/12293905.shtml

7. ДИТ «Новая индустрия» (New Industry Ventures) [Электронный ресурс] // Российская венчурная компания [Офиц. сайт].- Режим доступа: https://www.rvc.ru/investments/partnership_funds/sector_funds/newindustry/

8. Индустрия 4.0: как России не пропустить технологическую революцию [Электронный ресурс] // Цифровая Россия [Офиц. сайт].- Режим доступа: http://digital-russia.rbc.ru/articles/kak-rossii-ne-propustittekhnologicheskuyu-revolyutsiyu/

9. Инновации в России - неисчерпаемый источник роста [Электронный ресурс] // McKinsey \& Company [Офиц. сайт].- Июль 2018.- Режим доступа: https://www.mckinsey.com/ /media/McKinsey/Locations/Europe\%20 and\%20Middle\%20East/Russia/Our\%20Insights/Innovations\%20in\%20Russia/Innovations-in-Russia_web_lq-1. ashx

10. Инновации как системный феномен [Электронный ресурс] // ИСИЭЗ НИУ ВШЭ [Офиц. сайт].- Режим доступа: https://issek.hse.ru/news/105485423.html

11. Интеллектуальная добыча [Электронный ресурс] // Neftegaz.RU [Офиц. сайт]. - № 7 2018.- Режим доступа: https://magazine.neftegaz.ru/upload/iblock/76b/76bf39511534484fba5b29144ffdebac.pdf

12. Как инновации спасут нефтегаз [Электронный ресурс] // Сколково [Офиц. сайт].- Режим доступа: https:// sk.ru/news/b/press/archive/2014/10/24/kak-innovacii-spasut-neftegaz.aspx

13. Минэнерго и Минпромторг создают Центр компетенций импортозамещения в ТЭК [Электронный ресурс] // Министерство энергетики Российской Федерации [Офиц. сайт].- Режим доступа: https://minenergo.gov. $\mathrm{ru} / \mathrm{node} / 13609$

14. Нефтяные гиганты запустили блокчейн-платформу [Электронный ресурс] // Рамблер. Финансы [Офиц. сайт].- Режим доступа: https://finance.rambler.ru/markets/41368770

15. Об Ассоциации [Электронный ресурс] // Российское отделение Ассоциации тройной спирали [Офиц. сайт].Режим доступа: http://triplehelixassociation.com/about/ 
16. Путин заявил о необходимости увеличить ВВП в 1,5 раза к 2025 году [Электронный ресурс] // РБК [Офиц. сайт]. - Режим доступа: https://www.rbc.ru/rbcfreenews/5a97ca529a79475cfaf4b7cc

17. «Реализация топлива стала дополнительным социальным обязательством» [Электронный ресурс] // Коммерсантъ [Офиц. сайт].-- Режим доступа: https://www.kommersant.ru/doc/3896201

18. Рязанова О.Е. Институт промышленной собственности в инновационной экономике / О.Е. Рязанова.- Москва: ИИУ МГОУ, 2014.-266 с.

19. Рязанова О.Е., Золотарева В. П. Циркулярная экономика / О. Е. Рязанова, В. П. Золотарева.- Москва: КноРус, 2020.

20. Справедливый налог [Электронный ресурс] // Коммерсантъ [Офиц. сайт].- Режим доступа: https://www. kommersant.ru/doc/3828010

21. Теоретико-методологические аспекты инновационной деятельности организации: монография / Е. В. Назарова, О.Е., Сычева Е.И., Егорова Н.Е. и др.; под ред. О.Е. Рязановой.- Москва: ИИУ МГОУ, 2016. - 312 с.

22. Торговлю нефтью сажают на «цепь». Как блокчейн поможет нефтяникам [Электронный pecypc] // Forbes [Офиц. сайт].- Режим доступа: https://www.forbes.ru/biznes/355179-torgovlyu-neftyu-sazhayut-na-cep-kakblokcheyn-pomozhet-neftyanikam

23. Цифровая добыча нефти: тюнинг для отрасли [Электронный ресурс] // VYGON Consulting [Офиц. сайт].Июнь 2018.- Режим доступа: https://vygon.consulting/upload/ iblock/d11/vygon_consulting_digital_upstream. pdf

24. Что поможет оживать НИОКР в России и почему без них будет только хуже [Электронный ресурс] // РБК [Офиц. сайт].- Режим доступа: https://pro.rbc.ru/news/5c88b8989a79477f1c5ca723

25. Big Oil pledges $\$ 1$ billion for gas technologies to fight climate change [Electronic resource] // Reuters [Official site].- Available at: https://www.reuters.com/article/us-oil-climatechange-idUSKBN12Z158 